\title{
Determination of horizontal and vertical design spectra based on ground motion records at Lali tunnel, Iran*
}

\author{
F Moradpouri ${ }^{1, \star}$ and M Mojarab ${ }^{2}$ \\ ${ }^{1}$ Faculty of Mining, Petroleum \& Geophysics, Shahrood University of Technology, Shahrood, Iran \\ ${ }^{2}$ School of Mining, College of Engineering, University of Tehran, Tehran, Iran
}

\begin{abstract}
Most acceleration diagrams show high levels of unpredictability, as a result, it is the best to avoid using diagrams of earthquake acceleration spectra, even if the diagrams recorded at the site in question. In order to design earthquake resistant structures, we, instead, suggest constructing a design spectrum using a set of spectra that have common characteristics to the recorded acceleration diagrams at a particular site and smoothing the associated data. In this study, we conducted a time history analysis and determined a design spectrum for the region near the Lali tunnel in Southwestern Iran. We selected 13 specific ground motion records from the rock site to construct the design spectrum. To process the data, we first applied a base-line correction and then calculated the signal-to-noise ratio $\left(R_{\mathrm{SN}}\right)$ for each record. Next, we calculated the Fourier amplitude spectra of the acceleration pertaining to the signal window (1), and the Fourier amplitude spectra of the associated noise (2). After dividing each spectra by the square root of the selected window interval, they were divided by each other (1 divided by 2 ), in order to obtain the $R_{\mathrm{SN}}$ ratio (filtering was also applied). In addition, all data were normalized to the peak ground acceleration (PGA). Next, the normalized vertical and horizontal responses and mean response spectrum $(50 \%)$ and the mean plus-one standard deviation (84\%) were calculated for all the selected ground motion records at 5\% damping. Finally, the mean design spectrum and the mean plus-one standard deviation were plotted for the spectrums. The equation of the mean and the above-mean design spectrum at the Lali tunnel site are also provided, along with our observed conclusions.
\end{abstract}

Key words: Lali tunnel; ground motion record; response spectra; design spectra; signal processing CLC number: P315.9 Document code: A

\section{Introduction}

The construction of the Lali tunnel was executed in the Khuzestan Province of Southwestern Iran. The tunnel is located near Lali County and the cities of Shushtar, MasjedSoleiman and Dezfoul. Because the current road connecting MasjedSoleiman and Lali is flooded due to the impoundment of water in the Upper Gatvand Dam, a new road is being constructed between these two towns that makes use of the Lali tunnel.

The Lali tunnel has three sections: two eastern sections (tunnels 1 and 2) and one western section (tunnel

\footnotetext{
* Received 28 June 2012; accepted in revised form 25 July 2012; published 10 August 2012.

+ Corresponding author. e-mail: f. moradpouri@gmail.com

(c) The Seismological Society of China, Institute of Geophysics,

China Earthquake Administration, and Springer-Verlag Berlin Heidelberg 2012
}

3), which are connected to each other by the Lali Bridge (Figure 2). Tunnels 1 and 2 (east of the Lali Bridge) are $314 \mathrm{~m}$ and $238 \mathrm{~m}$, respectively (with a slope of $-3.5 \%$ ). In addition, tunnel 3 (west of the Lali Bridge) is $256 \mathrm{~m}$ long with a strike of approximately 300 and a slope of $-0.99 \%$. Ground level at the entrance and exit of the tunnel is $242.41 \mathrm{~m}$ and $251.41 \mathrm{~m}$, respectively. The maximum overburden height is $245.88 \mathrm{~m}$.

\section{Geology of the study region}

The Lali tunnels are located within the Mishan formation, which is mostly composed of marl. The tunnel system has an approximate strike of $300^{\circ}$ (tunnel 1 has little curvature), which is almost consistent with the existing bedding in the region. The bedding is composed of shale, marl and calcareous sandstone units. The thickness of the bedding and the varying erosional resistance 
of the units have resulted in fractional erosion. As a result, the more resistant sandstone units have an ele- vated morphology when compared to the less resistant shale and marl units (Mpradpouri and Mojarab, 2012).

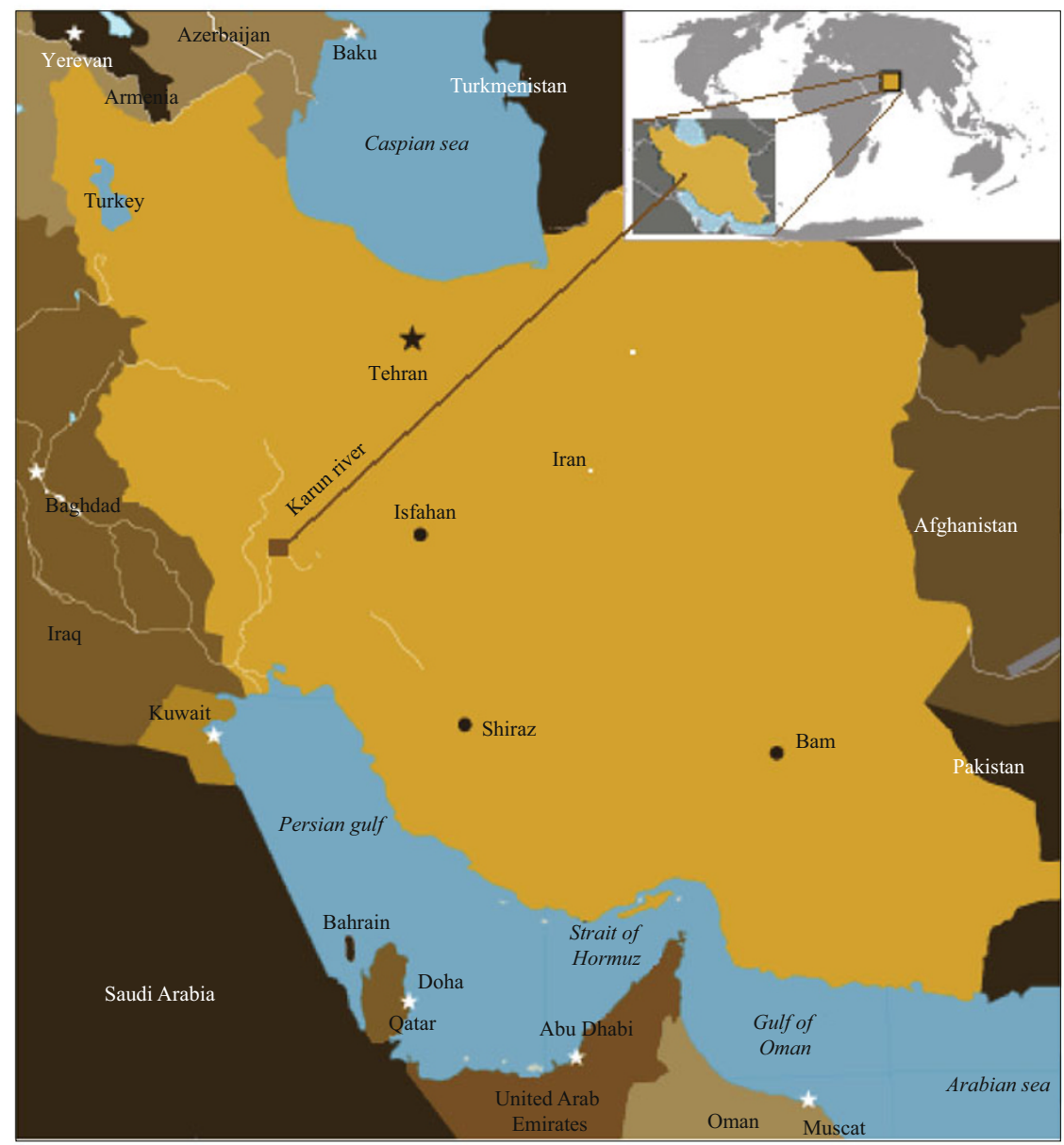

Figure 1 Map showing the location of the Lali tunnel.

\section{Soil type at Iran's ground mo- tion recording stations}

To determine the wave acceleration at specific sites, shear wave velocities recorded at nearby stations were used to estimate the ratio of horizontal component to vertical component $\left(F_{\mathrm{HV}}\right)$ and to calculate the fundamental soil frequency at individual sites. This allows for the calculation of the spectral ratio $\left(F_{\mathrm{HV}}\right)$ of the horizontal component with respect to the vertical component. Values corresponding to the horizontal component of the shear wave velocity are generally highest, followed by values of the amplitude of the compressive waves, which are, in turn, higher than values corresponding to the vertical component of the shear waves (Horike et al., 20002). If these waves enter into a new environment with physical properties differing from the bedrock (at a different shear wave rate), they will undergo a large change in frequency and amplitude. Therefore, use of a spectral ratio can give an indication of the resonance function at the site in question. To calculate the spectral ratio, the mean Fourier spectra of the smoothed horizontal components of the acceleration are divided by the vertical components obtained by the same method. If $S_{\mathrm{H} 1}(f)$ and $S_{\mathrm{H} 2}(f)$ are the Fourier amplitude spectra of the horizontal components of the acceleration, $S_{\mathrm{V}}(f)$ is the Fourier spectrum of the vertical component of the acceleration, and $T_{\mathrm{H} 1}, T_{\mathrm{H} 2}$, and $T_{\mathrm{V}}$ are the time windows for the aforementioned horizontal and vertical components of the acceleration, respectively, then the spectral ratio is equal to:

$$
R_{\mathrm{HV}}=\frac{\sqrt{S_{\mathrm{H} 1}(f)^{2} / 2 \sqrt{T_{\mathrm{H} 1}}+S_{\mathrm{H} 2}(f)^{2} / 2 \sqrt{T_{\mathrm{H} 2}}}}{S_{\mathrm{V}}(f) \mid T_{\mathrm{V}}} .
$$


By researching and identifying soil types from several of Iran's ground motion recording stations, Zaré (1999) was able to divide station soil types into four groups based on shear wave velocity and resonance fre- quency $(\mathrm{H} / \mathrm{V})$. These groups are classified as soil types 1 through 4 , with type 4 soils characterized as the least resistant (Table 1).

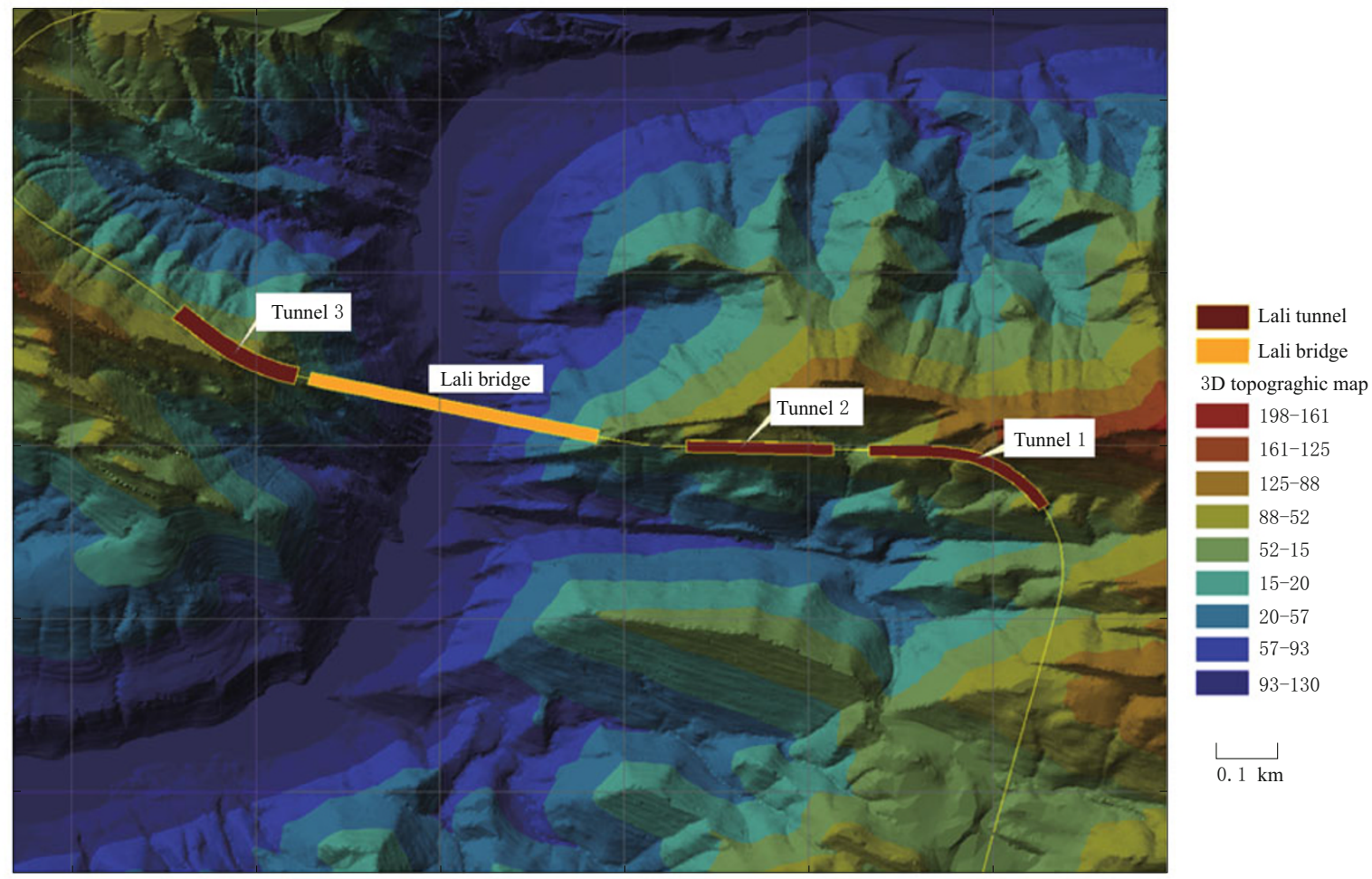

Figure 2 DEM map of the Lali tunnel system.

Table 1 Soil type classification for Iran's ground motion recording stations (Zaré, 1999)

\begin{tabular}{|c|c|c|c|}
\hline Soil class & Ratio of $\mathrm{H} / \mathrm{V}$ & Frequency domain & $v_{\mathrm{S}} / \mathrm{m} \cdot \mathrm{s}^{-1}($ upper $30 \mathrm{~m})$ \\
\hline \multirow{2}{*}{ Type I (Rock site) } & $\mathrm{H} / \mathrm{V} \geq 3$ & $f \geq 15 \mathrm{~Hz}$ & $v_{\mathrm{S}}>700$ \\
\hline & $\mathrm{H} / \mathrm{V} \leq 3$ & $f \leq 15 \mathrm{~Hz}$ & \\
\hline Type II (Hard alluvium site) & $\mathrm{H} / \mathrm{V} \geq 3$ & $f \geq 5-15 \mathrm{~Hz}$ & $500<v_{\mathrm{S}} \leq 700$ \\
\hline Type III & $\mathrm{H} / \mathrm{V} \geq 3$ & $f \geq 2-5 \mathrm{~Hz}$ & $300<v_{\mathrm{S}} \leq 500$ \\
\hline Type IV (Soft soil) & $\mathrm{H} / \mathrm{V} \geq 3$ & $f \leq 2 \mathrm{~Hz}$ & $v_{\mathrm{S}} \leq 300$ \\
\hline
\end{tabular}

\subsection{Seismogram selection}

In order to successfully extract design spectra, researchers require one or more suitable ground motion records, which are representative of bedrock and of the Earth's surface (Mhraz, 1980). In this section, ground response spectra are prepared to investigate ground motion acceleration in different periods $(T(s))$. These spectra are prepared based on ground motion recording data associated with some of the relatively large-scale earthquakes that have occurred in Iran and according to characteristics of the extensive seismic sources being stud- ied.

To select appropriate ground motion records, we focus on four data characteristics: (1) target magnitude, (2) the distance of the seismic source to the ground motion recording station, (3) the earthquake mechanism, and (4) the geological conditions. Using the above criteria, we adjust the characteristics for the individual site specifications (Zaré et al., 1999). Below, we list a number of ground motion records, including their statistical response spectra (Table 2 ). 
Table 2 Characteristics of the selected accelerograph stations

\begin{tabular}{|c|c|c|c|c|c|c|}
\hline Station & Record No. & $M_{\mathrm{W}}$ & Long. $/{ }^{\circ} \mathrm{E}$ & Lat. $/{ }^{\circ} \mathrm{N}$ & Epicentral distance $/ \mathrm{km}$ & Soil code \\
\hline Abbar & $1362 / 1$ & 7.3 & 48.95 & 36.93 & 40 & 1 \\
\hline Manjil & 1360 & 7.3 & - & - & 12 & 2 \\
\hline Ghaen & 1118 & 6.6 & 59.19 & 33.73 & 55 & 1 \\
\hline Dastgerd & 1058 & 6.1 & - & - & 18 & 2 \\
\hline Naghan-1 & $1054 / 1$ & 6.1 & 50.72 & 31.93 & 7 & 1 \\
\hline Boshruyeh & $1083 / 1$ & 7.4 & 57.42 & 33.87 & 40 & 1 \\
\hline Deyhuk & $1082 / 1$ & 7.4 & 57.51 & 33.27 & 18 & 1 \\
\hline Tabas & $1084 / 1$ & 7.4 & 56.94 & 33.59 & 3 & 1 \\
\hline Qaen & 1139 & 7.1 & - & - & 44 & 1 \\
\hline Avaj & $2749 / 1$ & 6.4 & 49.22 & 35.57 & 15 & 1 \\
\hline Qaen & 1043 & 6.4 & - & - & 10 & 1 \\
\hline MeshkinShahr & 1700 & 6.1 & 47.67 & 38.40 & 13.4 & 1 \\
\hline Kariq & $1833 / 2$ & 6.1 & 48.06 & 37.91 & 25.7 & 2 \\
\hline
\end{tabular}

\subsection{Processing}

All of the selected ground motion records (Table

2) have a signal to noise ratio greater than 3. During processing, we start with a base-line correction for each seismogram. Next, to calculate the signal-to-noise ratio of the ground motion record $\left(R_{\mathrm{SN}}\right)$, we divide the signal $(S(f))$ and noise $(N(f))$ windows obtained by the Fourier amplitude spectrum analysis by the square root of the window time-scale (Boore, 2001, 2002). The two resulting values are then divided to give:

$$
R_{\mathrm{SN}}=\frac{f_{\mathrm{S}}\left(t_{\mathrm{S}}\right) \sqrt{t_{\mathrm{S}}}}{f_{\mathrm{N}}\left(t_{\mathrm{N}}\right) \sqrt{t_{\mathrm{N}}}},
$$

where, $f_{\mathrm{S}}\left(t_{\mathrm{S}}\right)$ is the Fourier amplitude spectrum of the selected window, and $f_{\mathrm{N}}\left(t_{\mathrm{N}}\right)$ is the spectrum of the selected noise window. $t_{\mathrm{S}}$ and $t_{\mathrm{N}}$ are the times associated with the signal and noise windows, respectively. This process is performed after smoothing the Fourier spectra using a smoothing function developed by Konno and Ohmachi (1998), in which the appropriate amplitudes (when the signal-to-noise ratio is greater than the threshold value, e.g. 3) are included and smoothed in all frequencies. When we set a threshold for the signalto-noise ratio of 3 , the frequency level at which the $R_{\mathrm{SN}}$ spectral amplitude goes beyond this limit is referred to as the high-pass filter frequency. When the spectral amplitude is smaller than this limit, it is referred to as the low-pass filter frequency, expressed as:

$$
V_{f} \in\left[f_{\mathrm{HP}}, f_{\mathrm{LP}}\right], \quad R_{\mathrm{SN}} \geq 3 .
$$

The extent of smoothing in the present study is 0.4 . Fourier amplitude spectra are also used to display the frequency band of the signal-to-noise spectrum range. Based on the Fourier amplitude spectrum of acceleration which was presented by Brune (1970), the form of the spectra is compared before and after filtering.

\section{Design spectra}

It is important to properly select response spectra in order to generate desirable design spectra (Seed et al, 1976). Because there is significant variation in earthquake ground motion data, absolute response spectra should not be used. Likewise, before statistical calculations can be performed, data must be normalized with peak ground acceleration (PGA) values. Using statistical calculations, the mean and standard deviation of the spectral responses within a certain period are determined. When the width of a design spectrum is equal to the mean, it is referred to as the mean response spectrum (mean $=50 \%$ ). Alternatively, when the width is equal to the mean plus one standard deviation $(\sigma=0.84)$, a spectrum is referred to as an abovemean design spectrum (Hall et al., 1975; Mohraz et al., 1972).

In order to obtain normalized response spectra, response spectrum values for each component of the ground motion data are divided by the peak ground acceleration of the recorded component (Figures 3 and 4). These normalized response spectra are classified according to the geology at each station. Next, the mean and mean plus one standard deviation spectra for each soil type are obtained, with a damping of $5 \%$ (Figures 5 and 6). For ordinary structures, it is sufficient to accept ground motion parameters and reflection spectra that are close to the average values obtained from the existing statistical information in the region (mean with $50 \%$ confidence). For more important structures like dams and nuclear power plants, the earthquake data selected for use in the design spectra should be within the mean plus one standard deviation of the set of existing data for the region. 


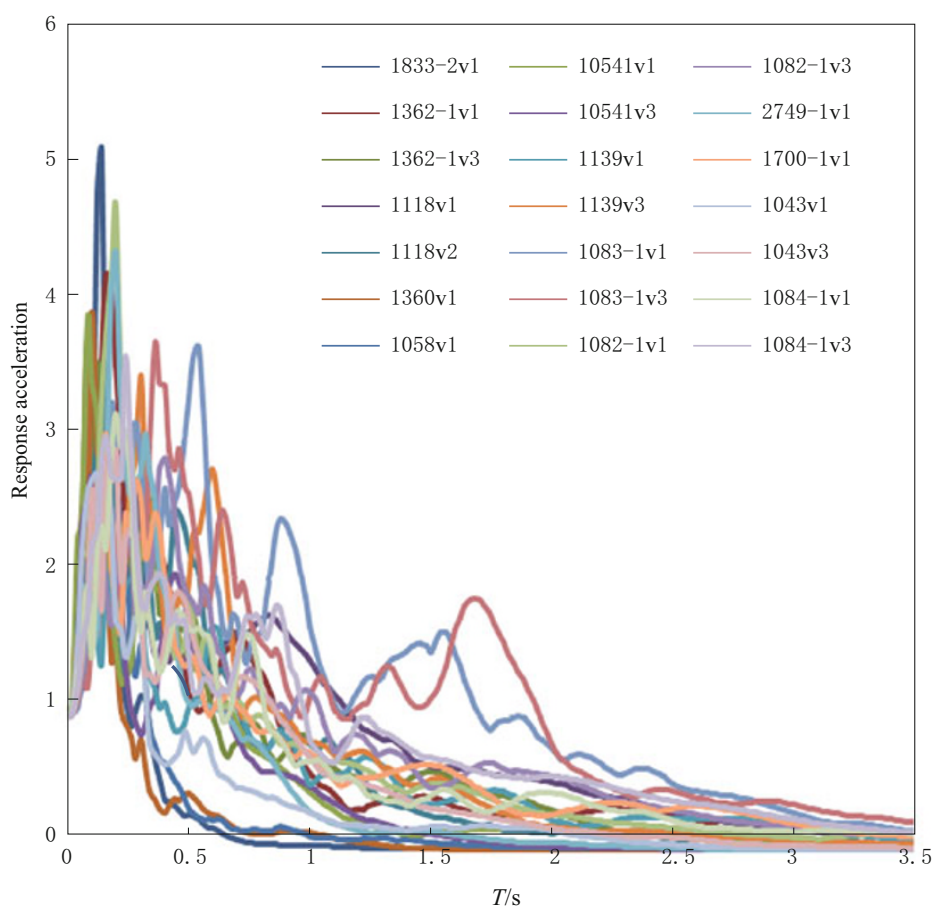

Figure 3 Response spectra normalized into PGA for the horizontal component with $5 \%$ damping.

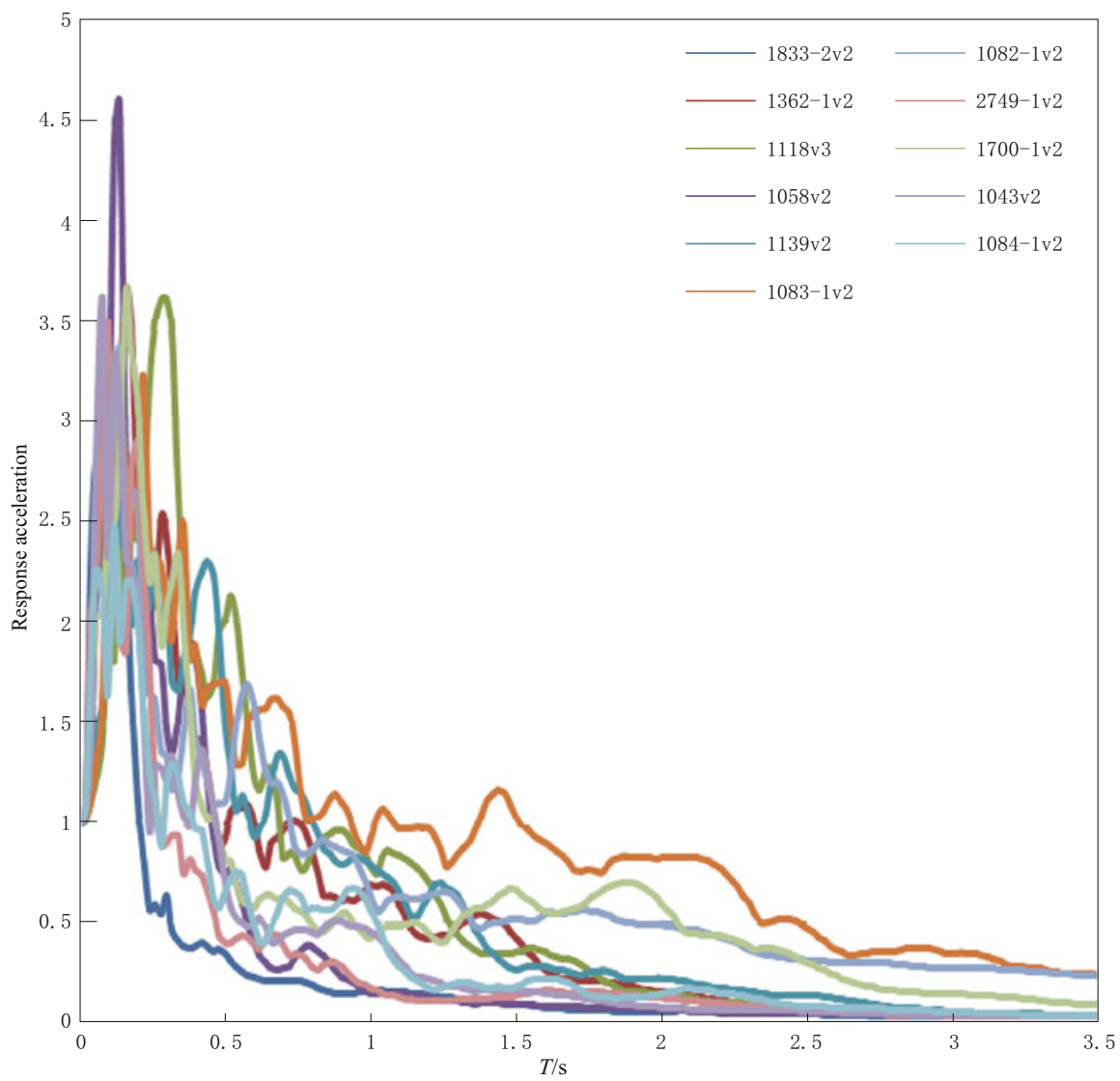

Figure 4 Response spectra normalized into PGA for the vertical component with $5 \%$ damping. 


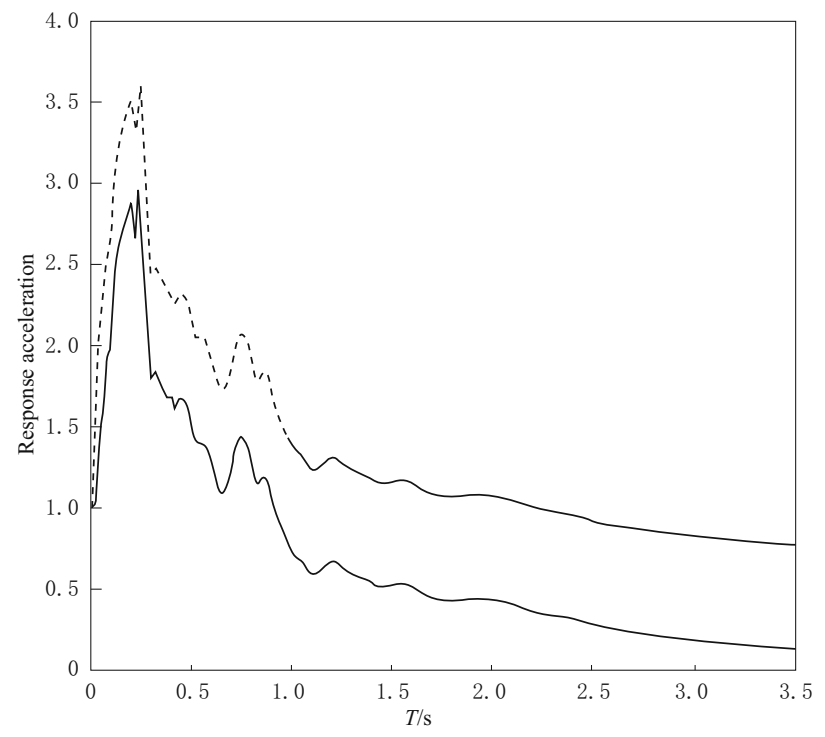

Figure 5 Mean response spectrum (50\%) and mean plus one standard deviation (84\%), normalized into PGA for the horizontal component with $5 \%$ damping.

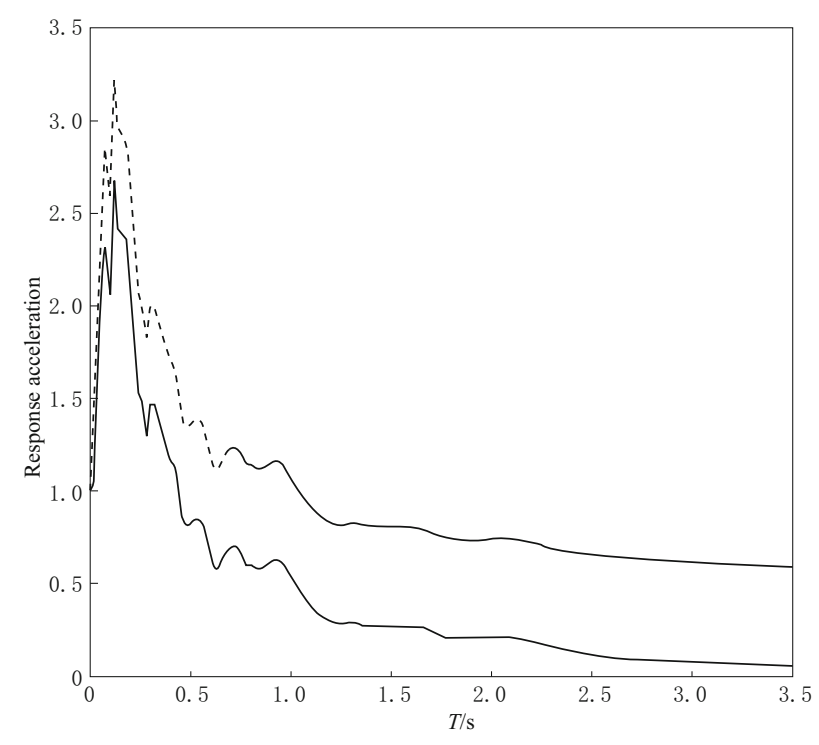

Figure 6 Mean response spectrum (50\%) and mean plus one standard deviation (84\%), normalized into PGA for the vertical component with $5 \%$ damping.

The response spectra represent the maximum ability of a structure to withstand a particular earthquake for a given degree of freedom. On the other hand, the smoothed design spectrum is characterized of the force $(F)$ or displacement corresponding to the period $(T)$ and the damping ratio. However, in some cases, the shape of the two spectra is identical. This conceptual difference should be taken into account. As a result, appropriately smoothed spectra are usually defined for design and evaluation purposes. These spectra are termed design response spectra. They do not represent the particular acceleration response from a single ground motion time-history, but rather, they are intended to be more representative of the general characteristics for a reasonable range of expected ground motions at a given site (Julian and Elnashai, 1999).

Values of the normalized design spectra for the horizontal and vertical components of the acceleration (PGA) at 5\% damping are calculated based on ground motion data processing and response spectra estimation. In Figures 7 through 10, mean design and mean plus one standard deviation are obtained for the horizontal and vertical components, respectively.

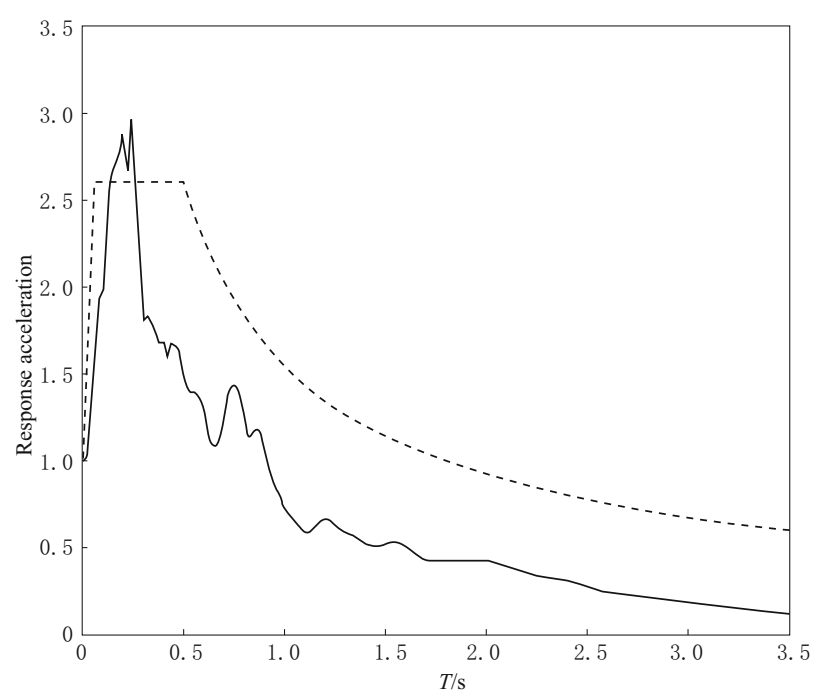

Figure 7 Mean design spectrum (50\%) for the horizontal component with $5 \%$ damping.

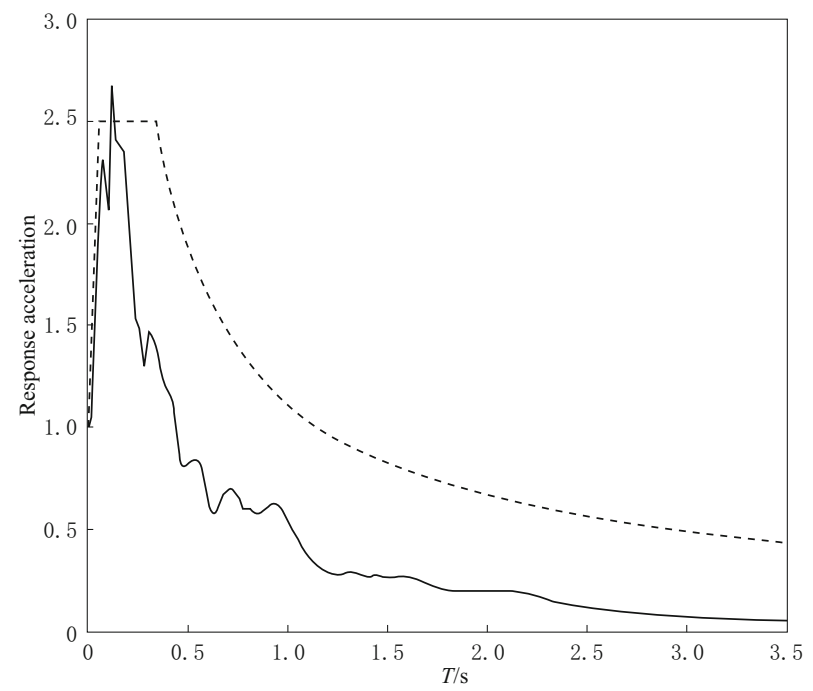

Figure 8 Mean design spectrum (50\%) for the vertical component with $5 \%$ damping. 


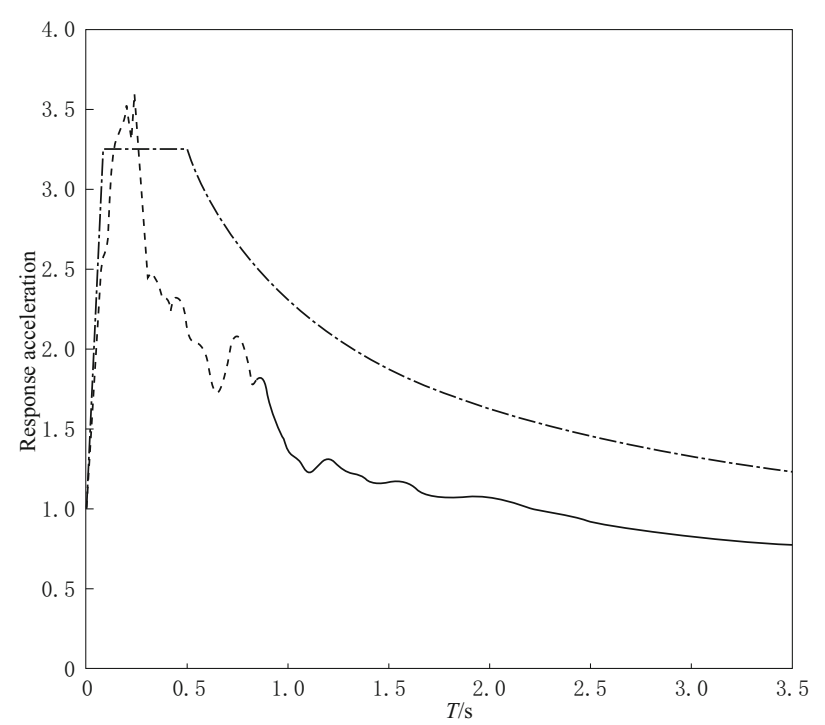

Figure 9 The above mean design spectrum (84\%) for the horizontal component with $5 \%$ damping.

\section{Conclusions}

The sites used in this study were categorized as either rock or hard soil and 13 records were processed accordingly. The response spectra of these records were calculated with $5 \%$ damping of the horizontal and vertical components of the ground motion data. The values were then normalized into PGA and weight averaged. Afterwards, the maximum mean and above-mean spectral acceleration for the two vertical and horizontal components were obtained, as well as the design spectrum for the mean and dominant periods, which are presented in Table 3 .

Because the accuracy of the recorded ground motion data used in this type of study can differ significantly (from a $F_{\mathrm{SN}}$ ratio point of view), each applied record has to be corrected using signal-to-noise calcu-

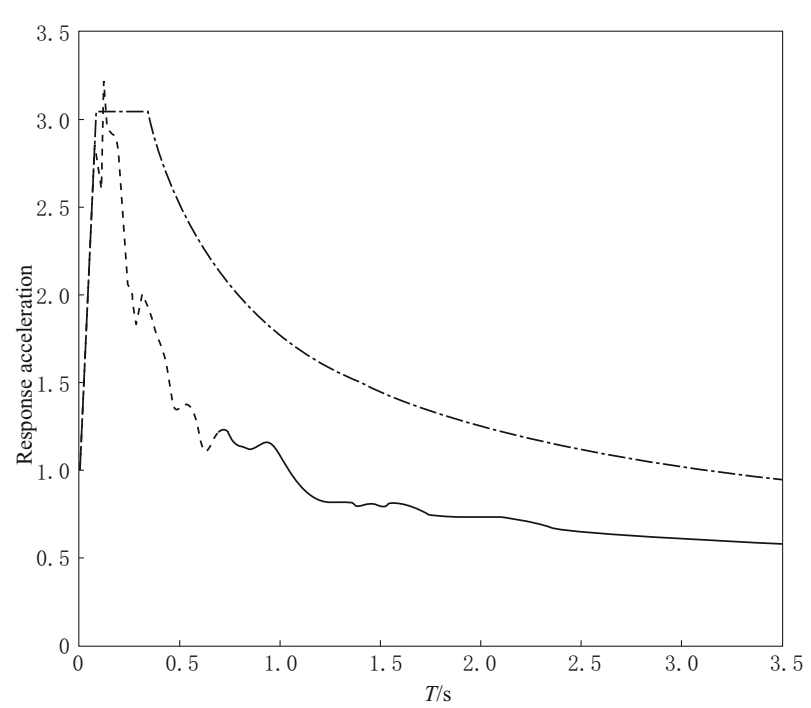

Figure 10 The above mean design spectrum (84\%) for the vertical component with $5 \%$ damping.

lations. As a further precaution, data with a signal-tonoise ratio of less than 3 should be eliminated for calculation and estimation of the attenuation relationship model.

Processing of recorded ground motion data should be performed with special care and by calculating highand low-pass frequency bands. Otherwise, inappropriate corrections (without calculation of the usable signal frequency band) result in the loss of existing signals and excessive noise. For a given period of 0.1 to $0.5 \mathrm{~s}$ with regard to the mean spectra and 0.06 to $0.6 \mathrm{~s}$ for the above-mean spectra, spectral values will be greater than those specified in the Code of Practice 2800 for the area in question. Therefore, we suggest a further investigation of the reflection spectra corresponding to the code of practice within these time periods.

Table 3 Results and equations for the Lali tunnel site

\begin{tabular}{lcc}
\hline \multicolumn{1}{c}{ Index } & Horizontal component & Vertical component \\
\hline Maximum mean spectral acceleration & 2.9 & 2.67 \\
\hline Maximum above- mean spectral acceleration & 3.6 & 3.2 \\
Dominant period $T$ & 0.24 & 0.12 \\
Mean design spectrum equation & $S_{a}=2.6(0.5 / T) / 3.4$ & $S_{a}=2.5(0.34 / T) / 3.4$ \\
Above-mean design spectrum equation & $S_{a}=3.24(0.5 / T) / 1.2$ & $S_{a}=3.03(0.34 / T) / 1.2$ \\
\hline
\end{tabular}

\section{References}

Boore D M (2001). Effect of baseline corrections on displacement and responsespectra for several recordings of the 1999 Chi-Chi, Taiwan, Earthquake. Bull Seismol Soc Am 91: 1 199-1 211.
Boore D M (2002). Comments on baseline correctionofdigital strong motion data: Examples from the 1999 Hector Mine, California Earthquake. Bull Seismol Soc Am 92: $1543-1560$.

Brune J (1970). Tectonic stress and the spectra of seismic 
shear waves from earthquakes. J Geophys Res 75(26): 4 997-5 009.

Hall W J, Mohraz B and Newmark N (1975). Statistical studies of vertical and horizontal earthquake spectra Nathan M. Newmark Consulting Engineering Services, Urbon, IL, 1975.

Horike M, Zhao B and Kawase H (2002). Comparison of site response characteristics inferred from microtremors and earthquake shear waves. Bull Seismol Soc Am March 2002.

Konno K and Ohmachi T (1998). Ground-motion characteristics estimated from spectral ratio between horizontal and vertical components of microtremor. Bull Seismol Soc Am 88: 228-241.

Julian J B and Elnashai A (1999). Displacement spectra for seismic design J Earthq Eng 3(1): 1-32.

Mohraz B (1980). A study of earthquake response spectra for different geological condition. Bull Seismol Soc Am 10(1): 305-321.
Mohraz B, Hall W J and Newmark N M (1972). A study of vertical and horizontal earthquake spectra Nathan M. Newmark Consulting Engineering Services, Urbon IL, AEC Report WASH-1255, 1972 .

Moradpouri F and Mojarab M (2012). Subsurface structural survey at Dez dam site based on seismic aspects. The First International Conf. on Dams \& Hydropowers. Tehran, Iran.

Seed H B, Vgas C and Lysmer J (1976). Site dependent spectra for earthquake resistance design. Bull Seismol Soc Am 66(1): 221-243.

Zaré M (1999). Contribution a letude des mouvements forts eu Iran , du catalogue aux loixdattenuations. [Ph.D Dissertation]. Université Joseph-Fourier, Grenoble, 237, pp1999.

Zaré M, Bard P Y and Ashtiany G M(1999). Site characterizations for the Iranian strong motion network $J$ Soil Dyn Earthq Eng (SDEE) 18(2): 11-123. 